\title{
Estudo de estratégias urbanísticas e ambientais para drenagem urbana na bacia do Ariri'
}

\section{Study of urban and environmental strategies for urban drainage in the Ariri basin}

\author{
Gonçalves, Glauciene1; Ponte, Juliano2;
}

\begin{abstract}
1 Universidade Federal do Pará, Belém-PA. Programa de Pós Graduação em Arquitetura e Urbanismo. glauciene.moraes.g@gmail.com

2 Universidade Federal do Pará, Belém-PA. Programa de Pós Graduação em

Arquitetura e Urbanismo. jximenes@ufpa.br
\end{abstract}

\begin{abstract}
RESUMO
A ausência de parâmetros urbanísticos de uso e ocupação do solo associada a grande carência de infraestrutura e saneamento básicos são as principais causas dos problemas com enchentes, inundações e alagamentos no município de Ananindeua. Logo, o objetivo desta pesquisa é realizar uma análise socioambiental da Bacia Hidrográfica do Ariri, situada entre Belém e Ananindeua, com a intenção de discutir a interferência desses e outros fatores na drenagem urbana e a importância da incorporação estratégica de parâmetros ambientais na elaboração do Plano Diretor (atualmente em revisão nos dois municípios). Este artigo é parte da pesquisa desenvolvida na dissertação de mestrado, apresentando, portanto, resultados parciais. A metodologia utilizada foi o estudo básico, auxiliado por pesquisas bibliográficas, documentais e pesquisa de campo. Constatou-se que os problemas de drenagem na bacia são resultados do assoreamento dos rios e impermeabilidade do território a montante, ocasionados pela ausência de planejamento e legislações urbanísticas específicas. Desse modo, essa pesquisa contribui para o estudo do meio ambiente urbano, na medida em que destaca a importância de diretrizes ambientais no planejamento das cidades.
\end{abstract}

Palavras-chave: Bacia Hidrográfica do Ariri, Planejamento urbano, Drenagem urbana.

\section{ABSTRACT}

The absence of urban planning parameters for land use and occupation associated with a major lack of basic infrastructure and sanitation are the main causes of problems with flooding, inundation and overflow in the municipality of Ananindeua. Therefore, the objective of this research is to perform a socio-environmental analysis of the Ariri Basin, located between Belém

1 GONÇALVES, Glauciene; PONTE, Juliano. Estudo de Estratégias Urbanísticas e Ambientais para Drenagem Urbana na Bacia do Ariri. In: II SIMPÓSIO NACIONAL DE GESTÃO E ENGENHARIA URBANA: SINGEURB, 2019, São Paulo. Anais... Porto Alegre: ANTAC, 2019. 
and Ananindeva, with the intention of discussing the interference of these and other factors in urban drainage and the importance of the strategic incorporation of environmental parameters in the elaboration of the Plan Director (currently under review in the two municipalities). This research started at the undergraduate level and continues as a master dissertation subject, presenting, therefore, partial results. The methodology used was the basic study, aided by bibliographical research, documentaries and field research. It was verified that the problems of drainage in the basin are results of the silting of the rivers and impermeability of the territory upstream, caused by the absence of planning and specific urban legislation. Thus, this research contributes to the study of the urban environment, in that it highlights the importance of environmental guidelines in city planning.

Keywords: Ariri Hydrographic Basin, Urban planning, Urban drainage.

\section{INTRODUÇÃO}

O município de Ananindeua é marcado por processos de ocupações espontâneas impulsionadas na década de 70 pelas fortes migrações vindas do interior do Estado. Essa população, sem recursos financeiros para obtenção de terra no mercado formal, estabeleceu-se em áreas de fragilidade ambiental gradativamente, ocasionando a degradação dos rios pela retirada da vegetação ciliar e a polvição, afetando a capacidade de vazão hídrica das bacias e provocando enchentes, inundações e alagamentos na região.

Historicamente, observa-se que as soluções adotadas configuram-se em obras e estruturas custosas, geralmente necessitando do remanejamento da população, encarecendo ainda mais o processo de melhoria urbana (BRANDÃO; PONTE, 2014). Dessa forma, o planejamento urbano e ambiental de bacias hidrográficas, por meio de legislações urbanísticas, atuam como medidas preventivas e significativamente mais econômicas.

Tais medidas, denominadas não estruturais, têm sido cada vez mais discutidas no âmbito global, como uma estratégia de gestão sustentável de bacias hidrográficas. Quando aliadas a medidas estruturais (intervenções físicas) não convencionais, possibilitam a criação de dinâmicas semelhantes aos processos naturais (ALVES, 2005; CANHOLI, 2005). No âmbito de reprodução desses processos destacam-se os dispositivos de infraestrutura verde que vêm sendo cada vez mais utilizados no exterior e em alguns casos no Brasil, associando o aspecto paisagístico a funções estruturais de manejo de águas urbanas em diversas escalas (PELLEGRINO; CORMIER, 2008).

A ausência de parâmetros urbanísticos no Plano Diretor de Ananindeva motiva a realização deste estudo, a fim de verificar a situação atual da região e evitar que os problemas de drenagem no município transformem-se em situações de difícil reversão, necessitando de operações de grande impacto ambiental e social.

Neste sentido, a escolha da Bacia Hidrográfica do Ariri constitui-se como um recorte importante, pois contém áreas de assentamentos urbanos antigos, assim como áreas de expansão urbana, recentemente alvejadas por empreendimentos imobiliários. A bacia situase em local estratégico, no limite dos municípios de Belém e Ananindeua (Figura 1) abrangendo parte de dois importantes eixos de expansão urbana, a BR 010 (Belém-Brasília) e a Rodovia Augusto Montenegro. 


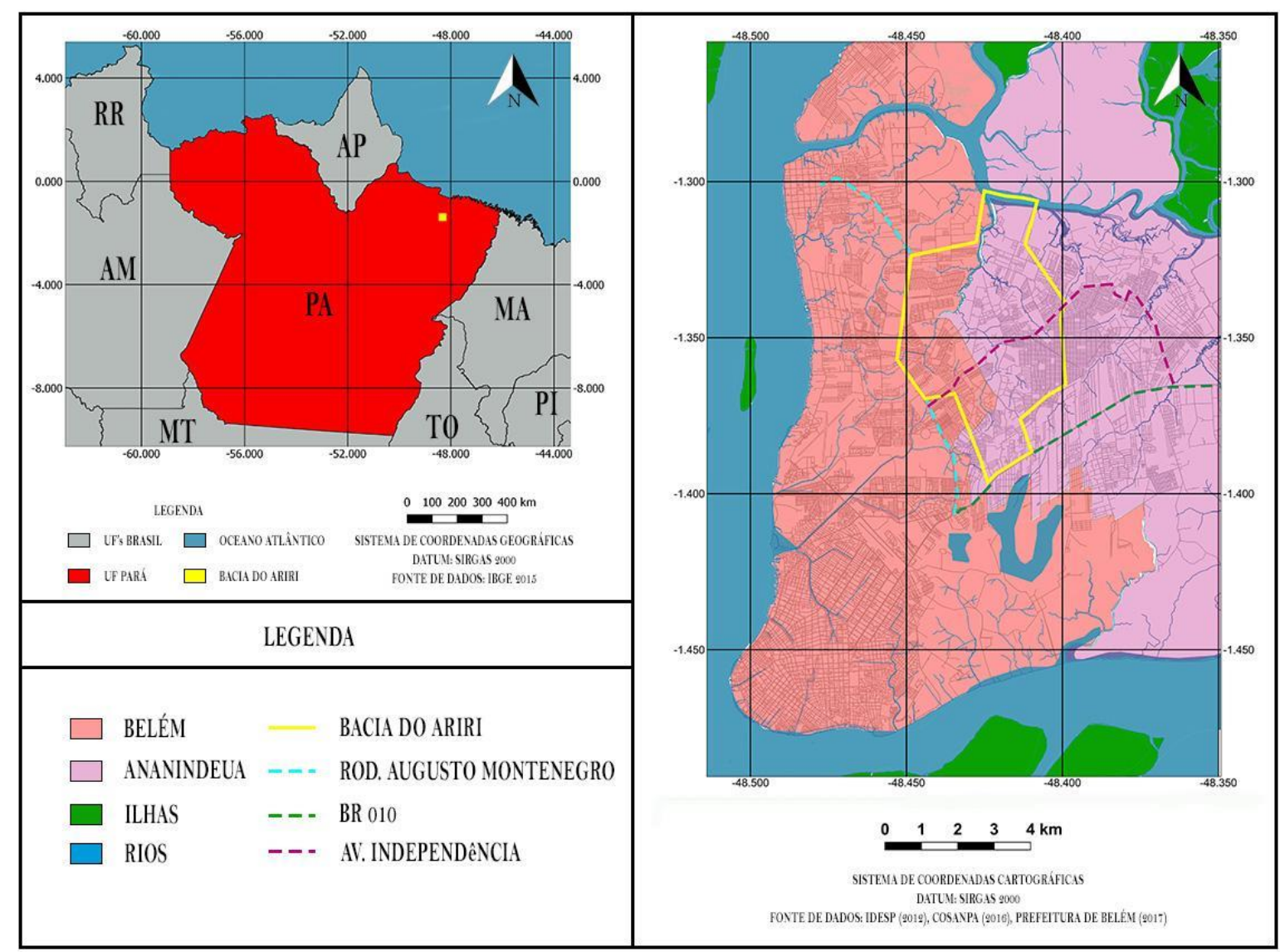

Fonte: O autor (2019)

\section{CARACTERÍSTICAS DA BACIA HIDROGRÁFICA DO ARIRI}

A bacia hidrográfica do Ariri possui cerca de $3727,73 \mathrm{Km}$, situando-se na divisa entre Belém e Ananindeva, porém sua maior porção territorial localiza-se em Ananindeva. É entrecortada de norte a sul pelo rio Iriri, abrangendo também outros igarapés menores. Possui tanto bairros de urbanização mais consolidada, quanto bairros em transição do rural para o urbano. A densidade populacional da bacia é de 69,55 hab/ha (VIEIRA, 2017), relativamente baixa quando comparada às outras bacias da RMB.

A permeabilidade é de $31 \%$, localizada principalmente nas cotas médias e baixas do sítio, coincidindo com a área vegetada, predominante no interior e nas porções norte da bacia. Também verificou-se que essas áreas possuem uma relação inversa com a localização de habitações, haja vista que à medida que se aproxima do interior e do norte da bacia, as edificações ficam mais esparsas e à medida em que se afasta, a vegetação e áreas permeáveis diminuem (Figura 2). Isso ocorre porque a maior parte das áreas vegetadas e permeáveis existentes correspondem a matas ciliares, além do uso do solo diferenciado nos bairros de expansão (situados ao norte) que ainda possuem um grande número de hortas, ocupações rurais e clubes de lazer.

A declividade do sítio é de apenas $0,16 \%$, valor abaixo do mínimo indicado (2\%), para a drenagem natural dos terrenos (MASCARÓ, 2008), necessitando, portanto, de alguma intervenção para auxiliar o escoamento da água superficial.

A capilaridade viária é de aproximadamente $0,027 \mathrm{~km} / \mathrm{ha}$, o que indica o baixo nível de acessibilidade na região proporcionada pela desarticulação viária, resultante da convivência entre diversas tipologias habitacionais que se estabeleceram sem qualquer preocupação de interligação com o sistema viário de entorno, criando uma verdadeira "colcha de retalhos". 
A bacia possui cerca de $54 \%$ do seu território ocupado por Aglomerados Subnormais (IBGE, 2010), o que indica a grande precariedade e a baixa renda da maior parte da população. Vale notar que, frequentemente, esses Aglomerados situam-se justamente em áreas próximas aos rios, ou sujeitas a inundações (Figura 3), caracterizando a bacia como uma região de grandes carências de cunho econômico, social e ambiental, agravadas pela fragilidade das legislações de controle do uso do solo e zoneamento.

Figura 2 - Relação áreas permeáveis / verdes x edificações

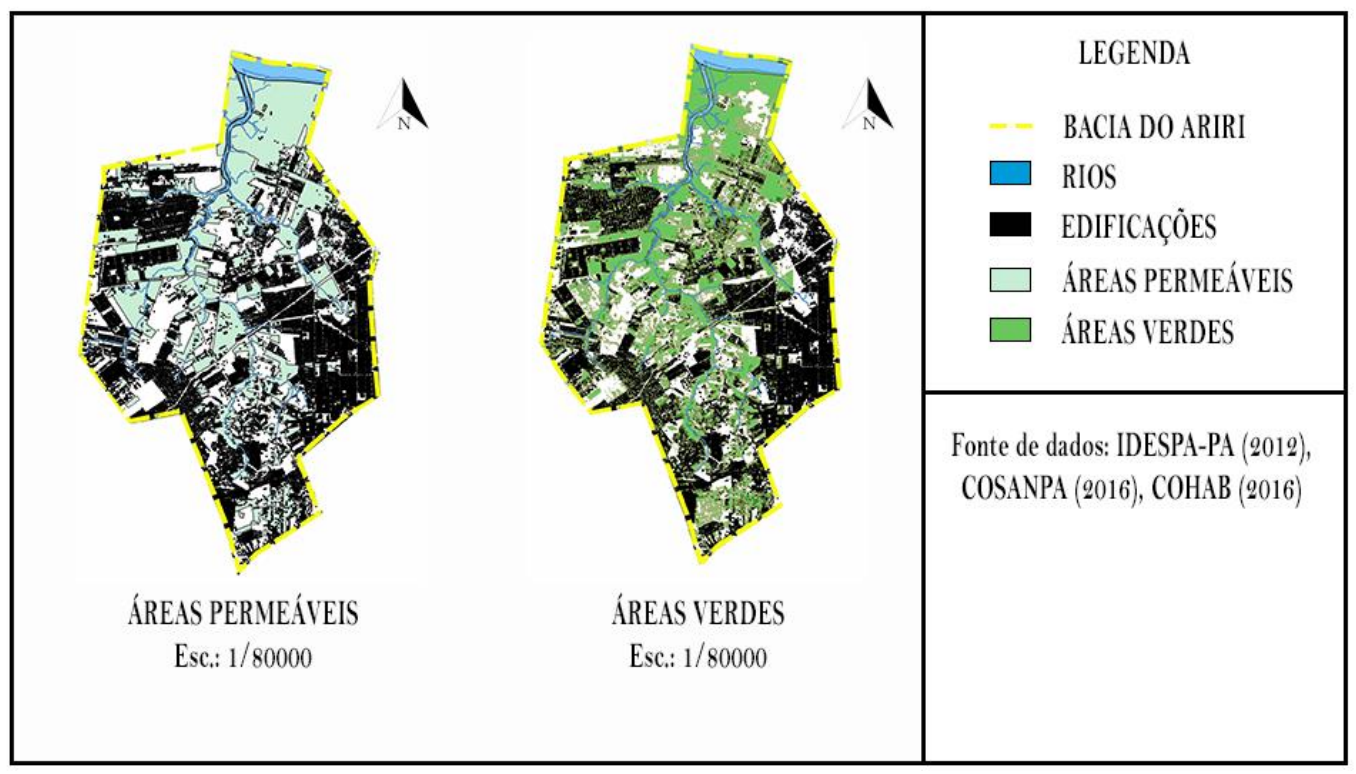

Fonte: O autor (2019)

Figura 3 - Risco de inundação

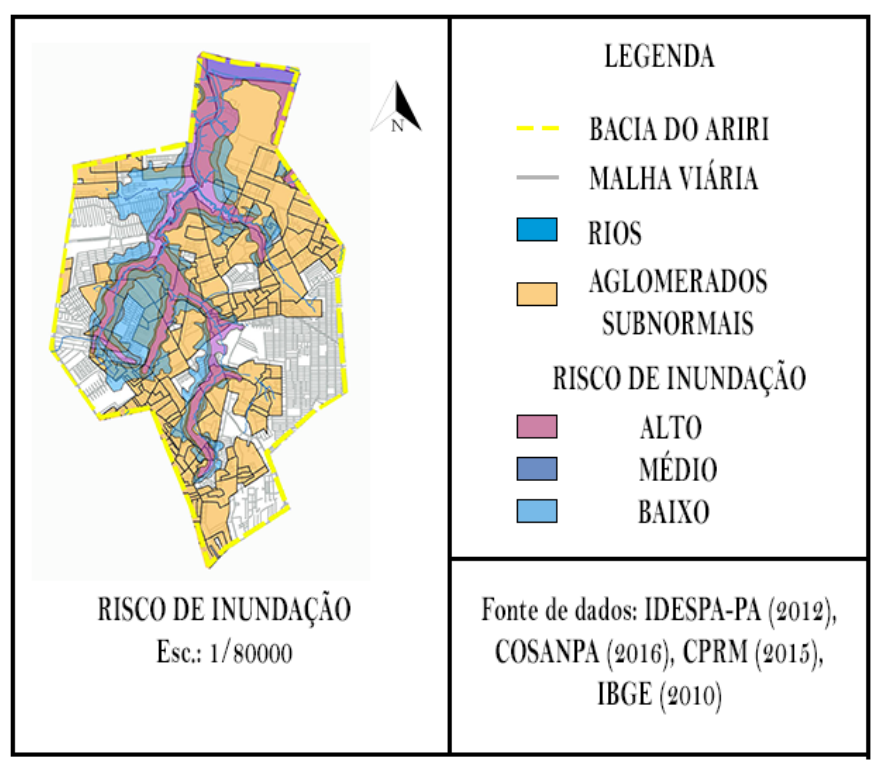

Fonte: O autor (2019) 


\subsection{O Plano Diretor de Ananindeua}

O Plano Diretor de Ananindeua (2006) não possui legislação específica de uso e ocupação do solo, sendo previsto apenas, e de caráter muito geral, a taxa de ocupação (T.O) e o índice de aproveitamento do solo (I.A), sem quaisquer valores máximos ou mínimos.

A ausência de T.O e I.A máximos, permite a implantação de empreendimentos que frequentemente não correspondem a infraestrutura local, gerando adensamentos não desejados e aumentando a precariedade, fenômeno recorrente principalmente nas áreas de expansão ou de médio adensamento. Enquanto isso, a falta de T.O mínima, permite a subutilização de terrenos em regiões com boa infraestrutura, garantindo a perpetuação dos processos de especulação imobiliária.

A inexistência de taxa de permeabilidade de lotes por zona e uso, permite que as áreas não edificadas dos lotes residenciais sejam totalmente impermeabilizadas, além de, no caso de empreendimentos comerciais, permitir a impermeabilização de grandes áreas destinadas a estacionamentos.

Percebe-se, portanto, que os índices existentes são bastante gerais e ineficientes, dando vazão a práticas que ferem princípios de funcionalidade e função social do uso do solo previstos no Estatuto da Cidade (2001). No contexto de revisão do Plano Diretor do município, que ocorre com atraso, coloca-se em questão a necessidade de implantação desses parâmetros, considerando-se também fatores ambientais para o planejamento sustentável da região.

\section{RESULTADOS}

Os resultados foram obtidos a partir da análise físico-ambiental da bacia que se deu pela elaboração de mapas de caracterização física e mapeamento de riscos de enchentes, obtidos por meio de dados da prefeitura, de instituições públicas e concessionárias de serviços locais. Também foram realizados cálculos básicos de balanço hidráulico, utilizando-se de dados do INMET, analisados com base no diagrama de Schueler (ARAÚJO et.al, 2008), e velocidade de escoamento da água, segundo Baptista; Coelho (2010).

Logo, verificou-se que existe um excedente de água que se acumula sobre a superfície da bacia o que, associado a baixa velocidade de escoamento e o atributo tipicamente plano do sítio, tende a provocar alagamentos, que se concentram nas partes mais baixas da região. Em tese, calculou-se que a correção do leito dos rios resolveria os problemas da bacia, causados principalmente pelo assoreamento dos corpos d'água localizados nas áreas mais urbanizadas e altas do território, contudo o volume de material a ser dragado exigiria um grande custo, sendo possível ser feito apenas em obras de macrodrenagem urbana. Desse modo, é necessária a utilização de medidas alternativas de drenagem urbana que consigam absorver esse volume excedente de água.

Observa-se também que os trechos mais altos do território da bacia são os que possuem melhor serviço de drenagem urbana e menos incidência de alagamentos, enquanto as partes mais baixas e precárias tendem a sofrer mais com esses transtornos. Isso se deve a uma transferência dos problemas, comumente ocasionada por sistemas que priorizam apenas o escoamento imediato das águas de um determinado trecho do território, mas que acabam se acumulando a jusante da bacia (CARNEIRO; MIGUEZ, 2011; ALVES, 2005).

Dessa forma, sugeriu-se estratégias de menor impacto socioambiental possível, visando a sustentabilidade do meio urbano e o uso de alternativas mais ecológicas, que buscam reproduzir os sistemas naturais de uma bacia hidrográfica e tratar o problema em sua origem. Essas estratégias se orientam a partir de um quadro de diretrizes e ações de drenagem sustentáveis, com o objetivo de atender as especificidades da bacia do Ariri, mas que podem ser adotadas como base para outras bacias hidrográficas. Muitas são ações simples que, quando seguidas, melhoram em muito o desempenho ambiental da bacia.

Elas se baseiam em: 
- Preservar áreas de várzea ainda não comprometidas por habitações, impedindo a ocupação e garantindo o espaço de alagamento natural dos rios, que ocorrem em determinados períodos de tempo (SPIRN, 1995).

- Recuperar as características naturais dos cursos d'água, por meio da correção da declividade dos leitos de rios, criação de faixas marginais de proteção e recomposição da vegetação ciliar.

- Utilizar métodos sustentáveis de drenagem estabelecendo parâmetros urbanísticos quantitativos de uso e ocupação do solo, implantando mecanismos de detenção e retenção do escoamento excedente, dispositivos de detenção controlada em vias estratégicas a fim de conduzir o escoamento para as áreas determinadas e melhorar a qualidade da água e criando áreas permeáveis como praças e parques.

Em se tratando da elaboração dos parâmetros urbanísticos, acredita-se que a melhor estratégia seja a associação entre o controle da densidade construtiva e populacional associada a utilização de dispositivos de infraestrutura verde com funções determinadas por zonas. Logo, foi previsto o uso de dispositivos de infiltração (biovaletas, canteiros pluviais e pavimentos permeáveis) e estruturas de reservação (cisterna, bacia de detenção e bacia de retenção).

Figura 4 - Estratégias sugeridas

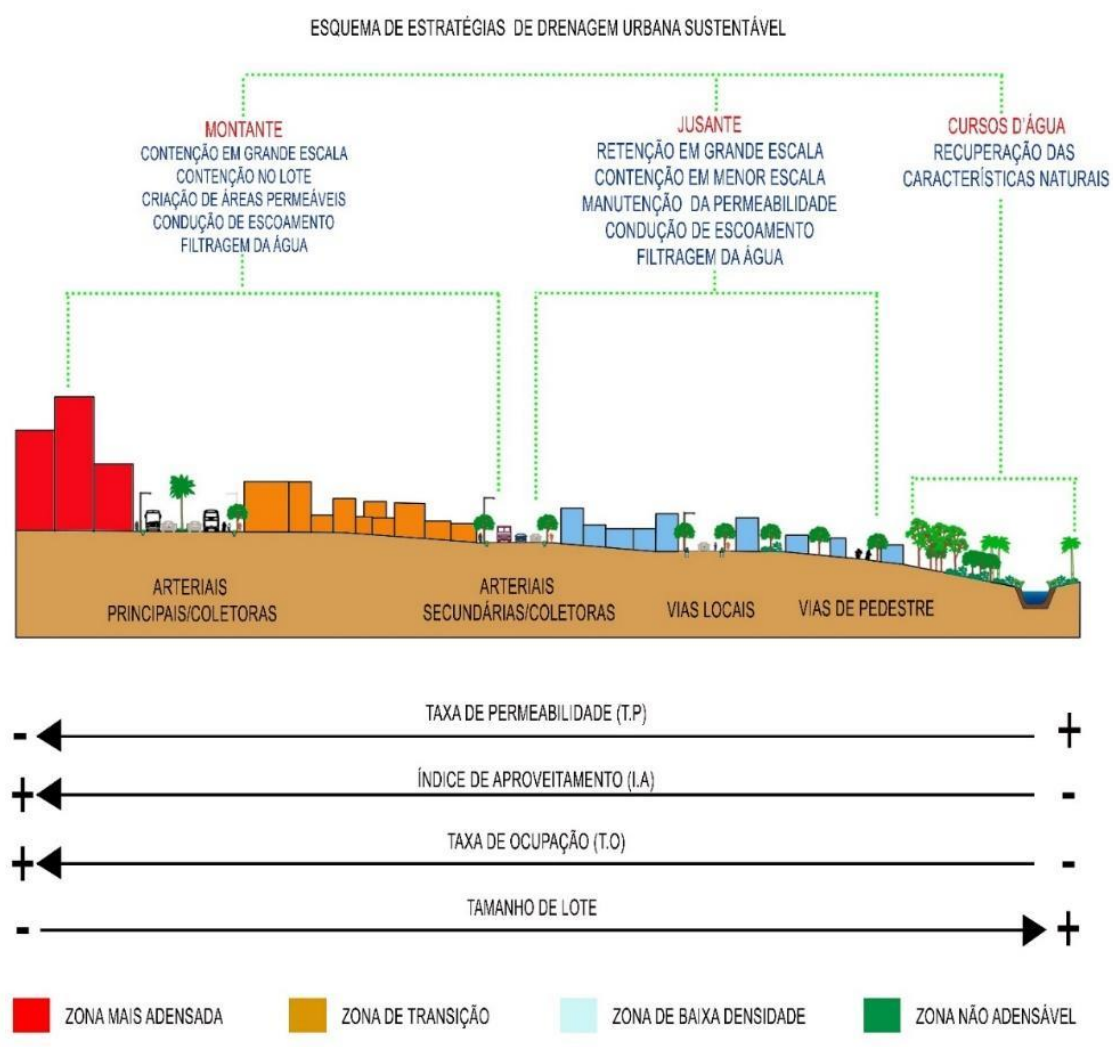

Fonte: O autor (2019)

\section{CONCLUSÃO}

O caráter chuvoso da região e o território tipicamente plano associados a processos de impermeabilização das áreas mais altas e o assoreamento dos rios, provocados pela retirada da vegetação de proteção e a poluição dos mesmos, resultam no aumento de volume de água superficial e diminuição da velocidade de escoamento, criando um cenário propício a 
ocorrência de inundações e alagamentos. Soluções de drenagem comumente adotadas, que se preocupam apenas com o rápido escoamento da água, tendem a transferir esses problemas até as áreas mais baixas da bacia, que também são as mais precárias, causando danos materiais e de risco a saúde, haja vista que água leva impurezas presentes no meio urbano.

A adoção de estratégias que atuem na legislação urbanística e no zoneamento da cidade, pode prevenir o agravo do problema ao restringir a ocupação em áreas de acomodação natural do rio, controlar o adensamento e prever áreas permanentemente permeáveis nas regiões mais altas, além de taxas mínimas de permeabilidade do solo, adequadas a cada zona do território. Em conjunto, podem ser adotadas estratégias de utilização de dispositivos de infraestrutura verde, juntamente com os equipamentos de drenagem convencionais, auxiliando na reserva da água da chuva, na escala intralote e urbana, podendo ser temporária nas partes mais altas do sítio e permanentes nas partes mais baixas, associadas aos usos compatíveis de esporte, lazer e equipamentos públicos.

Contudo, a implantação desses métodos depende em grande parte da aceitação por parte da população, de um amplo trabalho de educação ambiental e adaptação das tecnologias às especificidades locais. Esta pesquisa, portanto, serve como um ponto de partida para o aprofundamento de diversos estudos que visem a utilização de diretrizes mais sustentáveis e implantação de novos métodos que busquem uma aproximação com os processos naturais e diminuam o impacto causado ao meio ambiente e ao ser humano.

\section{REFERÊNCIAS}

ALVES, Elisânia Magalhães. Medidas não estruturais na prevenção de enchentes em bacias urbanas: cenários para a bacia do gregório. 2005. Dissertação (mestrado em Ciências da Engenharia Ambiental) São Carlos. Disponível em: < http://livros01.livrosgratis.com.br/cp012266.pdf> Acesso em julho de 2018.

ANANINDEUA. Lei Municipal $n^{\circ} 2.237 / 06$, de 06 de outubro de 2006. Institui o Plano Diretor de Ananindeua e dá outras providências. Câmara Municipal, Ananindeua, PA, 06 out. 2006. Disponível em: <

http://www.ananindeua.pa.gov.br/public/arquivos/legislacao/LEl_No._2237.pdf>. Acesso em: 19/06/2018.

ARAUJO; Gustavo Henrique de Sousa; ALMEIDA; Josimar Ribeiro de; GUERRA, Antônio José Teixeira. Gestão ambiental de áreas degradadas. Rio de Janeiro: Bertrand Brasil, 2008.

BAPTISTA, Márcio Benedito; COELHO, Maria Lara Pinto. Fundamentos de Engenharia Hidráulica. 473 p. 3 ed. rev. E ampl. Editora UFMG. Belo Horizonte, 2010.

BRASIL. Estatuto da Cidade - Lei n. 10257, de 10 de julho de 2001. Regulamenta os arts. 182 e 183 da Constituição Federal, estabelece diretrizes gerais da política urbana e dá outras providências. Diário Oficial da União. Brasília, DF, 10 jul. 2001. Disponível em: <http://www.planalto.gov.br/ccivil_03/leis/leis_2001/110257.htm>. Acesso em: 13 dez. 2014.

CANHOLI, Aluísio Pardo. Drenagem Urbana e Controle de Enchentes. Ed. Oficina de textos. São Paulo, 2005.

CARNEIRO, Paulo Roberto Ferreira. MIGUEZ, Marcelo Gomes. Controle de inundações em Bacias Hidrográficas Metropolitanas. São Paulo: Annablume, 2011.

CORMIER, N. S.; PELLEGRINO, P. R. M. Infra-estrutura verde: um a estratégia paisagística para a água urbana. Paisagem ambiente: ensaios, São Paulo, n. 25, p. 125-142, 2008. 
GONÇALVES, Glauciene Moraes. Proposta de intervenção urbanística para mitigação de enchentes. 2019. 168 f. Trabalho de Conclusão de Curso (graduação) - Faculdade de Arquitetura e Urbanismo (FAU), Universidade Federal do Pará (UFPA), Belém, 2019.

MASCARÓ, Juan Luis (org.). Infra-estrutura da paisagem. Porto Alegre: Masquatro Editora, 2008.

IBGE (Instituto Brasileiro de Geografia e Estatística). Censo demográfico 2010. Rio de Janeiro: IBGE, 2010. Disponível em: <www.censo2010.ibge.gov.br>.

SPIRN, Anne Whiston. O Jardim de Granito. São Paulo: EDUSP, 1995.

VIEIRA, Celso Taynan Martins. Construção de base cartográfica e estatística: subsídio para análise urbanístico-ambiental de drenagem urbana na Região Metropolitana de Belém (RMB). Relatório técnico-científico. 2015-2017. Laboratório Cidades da Amazônia. Faculdade de Arquitetura e Urbanismo (FAU), Universidade Federal do Pará, Belém (UFPA), 2017.

XIMENES, JUliano; BRANDAO, A. J. D. N. . Subsídios urbanísticos para um plano metropolitano de drenagem urbana, Região Metropolitana de Belém, Pará. In: III ENANPARQ - Cidade, arquitetura e projeto: uma construção coletiva, 2014, São Paulo; Campinas. Anais do III ENANPARQ. São Paulo; Campinas: Universidade Presbiteriana Mackenzie; Pontifícia Universidade Católica de Campinas, 2014. v. 1. 